\title{
Founder Mutation for $\alpha$-sarcoglycan- LGMD2D in a Magdalen Islands Acadian Cluster
}

\author{
M. Tétreault, M. Srour, J. Allyson, I. Thiffault, L. Loisel, Y. Robitaille, \\ JP. Bouchard, B. Brais
}

\begin{abstract}
Background: We have recruited a group of four living and reviewed the records of six deceased distantly related FrenchCanadians of Acadian descent affected by a childhood-onset form of recessive limb-girdle muscular dystrophy (LGMD). All cases originate from the small archipelago of the Magdalen Islands (population: 13,000) isolated in the Gulf of St-Lawrence. Methods: Based on the likely sharing of the same founder mutation we completed a 319K SNPs genome-wide scan to identify the disease locus and then screen candidate genes in this region. Results: All patients had normal initial motor milestones. They presented with limb girdle weakness at the average age of seven years (5-11). Progressive weakness led to loss of ambulation at a wide range of ages (10-39). Patients also developed macroglossia, large calves and mild to moderate contractures, hyperlordosis and decreased pulmonary function. Creatine kinase levels were elevated $(1,800-10,000 \mathrm{U} / \mathrm{L})$ in the first decades, but decreased with progression of disease. Homozygosity mapping uncovered a shared chromosomal region of $6.33 \mathrm{Mb}$. The alpha sarcoglycan $(S G C A)$ gene, mutated in LGMD2D, lay in this candidate interval. Sequencing of all SGCA exons uncovered a shared homozygous missense mutation (c.229C $>$ T, p.R77C), the most common SGCA mutation internationally reported. Using demographic data, we estimated a high carrier rate of $1 / 22$. Conclusion: The p.R77C mutation has also been observed in many populations, including in France and Spain (Basques). This corresponds to the first reported recessive founder disease for the Magdalen Islands, an archipelago settled in the XIXth century, largely by Acadian immigrants.
\end{abstract}

RÉSUMÉ: Identification d'une mutation fondatrice dans le gène $\alpha$-sarcoglycan dans une cohorte acadienne originaire des Iles de la Madeleine. Objectif : Nous avons recruté un groupe de quatre patients atteints ainsi que révisé le dossier de six patients décédés ayant une parenté lointaine, tous Canadiens français de descendance acadienne, atteints d'une forme récessive de dystrophie musculaire des ceintures (LGMD) débutant dans l'enfance. Tous les cas proviennent des Iles de la Madeleine, un petit archipel dans le Golf du St-Laurent. Méthode : L'apparentement éloigné suggère fortement le partage d'une mutation fondatrice. Nous avons donc complété un criblage entier du génome avec 319K SNP afin d'identifier le locus de la maladie et d'examiner les gènes candidats dans cette région. Résultats : Tous les patients ont eu un développent moteur normal. La faiblesse au niveau des ceintures a été observée en moyenne vers 1'âge de 7 ans (5-11). La faiblesse musculaire s'est accentuée avec la progression de la maladie, menant à la perte de la marche à des âges très variés (10-39). Les patients ont aussi développé une macroglossie, une hypertrophie des mollets, des contractures légères à modérées, une hyperlordose et une diminution de la fonction pulmonaire. Les niveaux de créatine kinase étaient élevés dans les premières décennies, mais ont diminué avec la progression de la maladie. L'analyse de cartographie par homozygocité a permis l'identification d'une région chromosomique partagée de $6.33 \mathrm{Mb}$. Le gène de l' $\alpha$-sarcoglycan (SGCA), muté dans la LGMD2D, était situé dans cette région candidate. Le séquençage de tous les exons du gène SGCA a révélé une mutation faux-sens homozygote (c.229C>T; p.R77C) partagée entre tous les individus atteints. Cette mutation est la plus rapportée à l'échelle internationale. À l'aide de données démographiques, nous avons estimé un taux de porteurs élevé, soit de 1/22. Conclusion : La mutation p.R77C a également été observée dans plusieurs populations, dont celles de la France et de l'Espagne (Basques). Cette étude correspond au premier effet fondateur pour une maladie récessive à être associé aux Iles de la Madeleine, un archipel peuplé au 19e siècle en grande majorité par des immigrants acadiens.

Can. J. Neurol. Sci. 2011; 38: 747-752

Limb-girdle muscular dystrophies (LGMD) are characterized by weakness and wasting of shoulder and pelvic-girdle muscle ${ }^{1-}$ 3 , with typical sparing of the facial muscles ${ }^{4}$ and characteristic dystrophic muscle biopsy ${ }^{1,2}$. The various forms of LGMD have been classified based on their modes of transmission, chromosomal loci or their mutated genes. To date, seven autosomal dominant forms (LGMD1A-G) and sixteen autosomal recessive forms (LGMD2A-O and $Q$ ) have been characterized $^{5}$. The different autosomal recessive LGMDs (ARLGMDs) display some epidemiological or clinical differences that may help their clinical distinction ${ }^{6,7}$. All of the LGMDs are rare diseases and some of them have only been described in a few families or ethnic groups ${ }^{1,2}$.
Limb-girdle muscular dystrophies demonstrate great phenotypic variability even within the LGMD subtype. Sometimes, this variability can be seen within a single multiplex

\footnotetext{
From the Laboratoire de neurogénétique de la motricité (MT, MS, JA, IT, LL, BB), Centre d'excellence en Neuromique de 1'Université de Montréal, CRCHUM; Department of Molecular Neurogenetics (IT), Montreal Neurological Institute; Département de pathologie (YR), CHU-Sainte-Justine, Montreal; Département des sciences neurologiques (JPB), CHAUQ - Hôpital de l'Enfant-Jésus, Université Laval, Québec, QC, Canada.

Received February 28, 2011. Final Revisions Submitted April 20, 2011 Correspondence to: Bernard Brais, Laboratoire de neurogénétique, M4211-L3, Hôpital Notre-Dame-CHUM, 1560 Sherbrooke Est, Montreal, Quebec, H2L 4MI, Canada,
} 
family ${ }^{1,2}$. The sarcoglycanopathies (LGMD2C-F) are caused by mutations in $\alpha, \beta, \delta$ and $\gamma$ sarcoglycan ${ }^{8}$. Sarcoglycanopathies primarily involve wasting of the shoulder and girdle muscles along with calf hypertrophy ${ }^{9}$ and share some clinical similarities with Duchenne Muscular Dystrophy ${ }^{7}$. No significant clinical features clearly distinguish the different sarcoglycanopathies. The four components of the sarcoglycan complex are transmembrane glycoproteins which together with sarcospan, dystrophin, dystroglycans, syntrophins, and $\alpha$-dystrobrevin, constitute the dystrophin-glycoprotein complex (DGC) ${ }^{7}$. The DGC complex acts as a linker between the cytoskeleton of the muscle cell and the extracellular matrix, providing mechanical support to the plasma membrane during myofiber contraction. Mutations in any of the four sarcoglycans cause a reduction or absence of the defective protein and affect the expression of the other subunits ${ }^{8}$.

In Europe and North America the majority of the patients deficient for the sarcoglycans proteins are affected by LGMD2D which is caused by mutations in $\alpha$-sarcoglycan $(S G C A)^{7,10}$. In $S G C A$, there is a high predominance of the c.229C $>$ T (p.R77C) mutation. This mutation was found in unrelated populations and on different haplotype backgrounds. The frequency was estimated at $95 \%$ in the Finnish population and $30 \%$ in other populations $^{11}$. In this study, we report eight French-Canadian families of Acadian descent (Magdalen Islands) carrying the p.R77C mutation. This is the first described founder effect for a recessive genetic disease documented for this eastern Canada archipelago.

\section{SubJeCTS AND Methods}

\section{Clinical evaluation and DNA isolation}

We have identified a cohort of four living and six deceased individuals belonging to eight different distantly related FrenchCanadian families from the Magdalen Islands affected by a childhood-onset LGMD (Figures 1,2). All living cases underwent a detailed neurological examination by experienced neurologists (BB, JPB). Family members of living and deceased cases were recruited for genetic analysis. This project was approved by institutional Ethics Committee of the Centre de recherche du CHUM. Informed consent was obtained from all patients and all participating living family members. Genomic DNA was extracted from peripheral blood lymphocytes using a standard method or by saliva using the Oragene DNA extraction kit (DNA Genotek, Ottawa Canada).

\section{Genome Scan}

A genome wide scan with the Illumina Hap300 single nucleotide polymorphisms (SNP) chip (319K SNPs) was conducted at Genome Quebec Innovation Center, McGill University (Montreal, QC, Canada) on four affected individuals and three non-affected family members. The SNPs were analyzed for homozygosity mapping using Beadstudio software from Illumina (San Diego, CA, USA).

\section{Pathological analysis}

Muscle biopsies were performed prior to this study in different centers using standard techniques on four patients (patients I, II, III and IV).

\section{Sequencing of SGCA}

Polymerase chain reaction (PCR) primers were designed using ExonPrimer (http://genome.ucsc.edu) and synthesized by Invitrogen (CA, USA). Polymerase chain reactions for the screening of candidate genes were performed using 40ng genomic DNA in $10 \mu \mathrm{L}$ PCR reactions containing $1 \mathrm{X}$ PCR reaction buffer, $3 \mathrm{nM} \mathrm{MgCl}_{2}, 10 \mu \mathrm{M}$ primer mix, and $0.4 \mathrm{U}$ taq DNA polymerase (Qiagen, CA, USA). For amplification reaction a touchdown program was used. Sequencing analyses

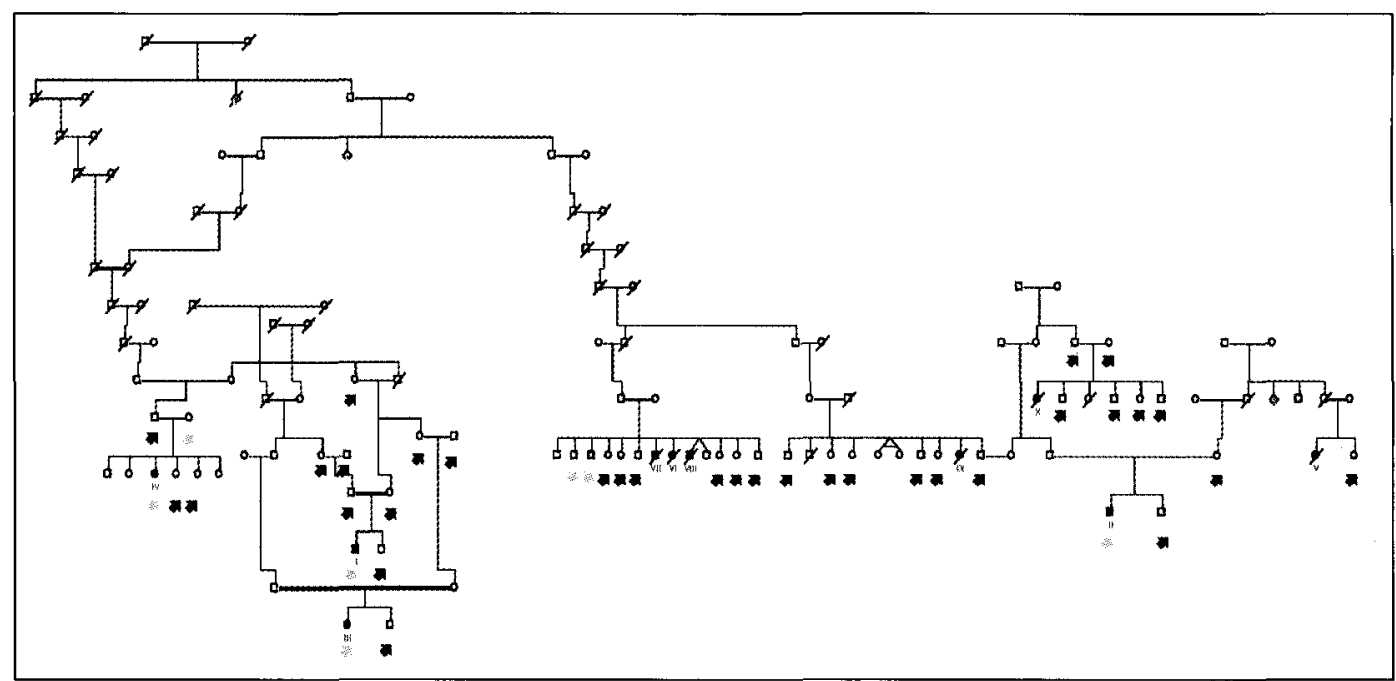

Figure 1: Pedigree for the large French-Canadian family from the Magdalen Islands affected by a LGMD with a childhood onset. Arrows: individuals recruited; Grey arrows: individuals sent for SNP genotyping. 


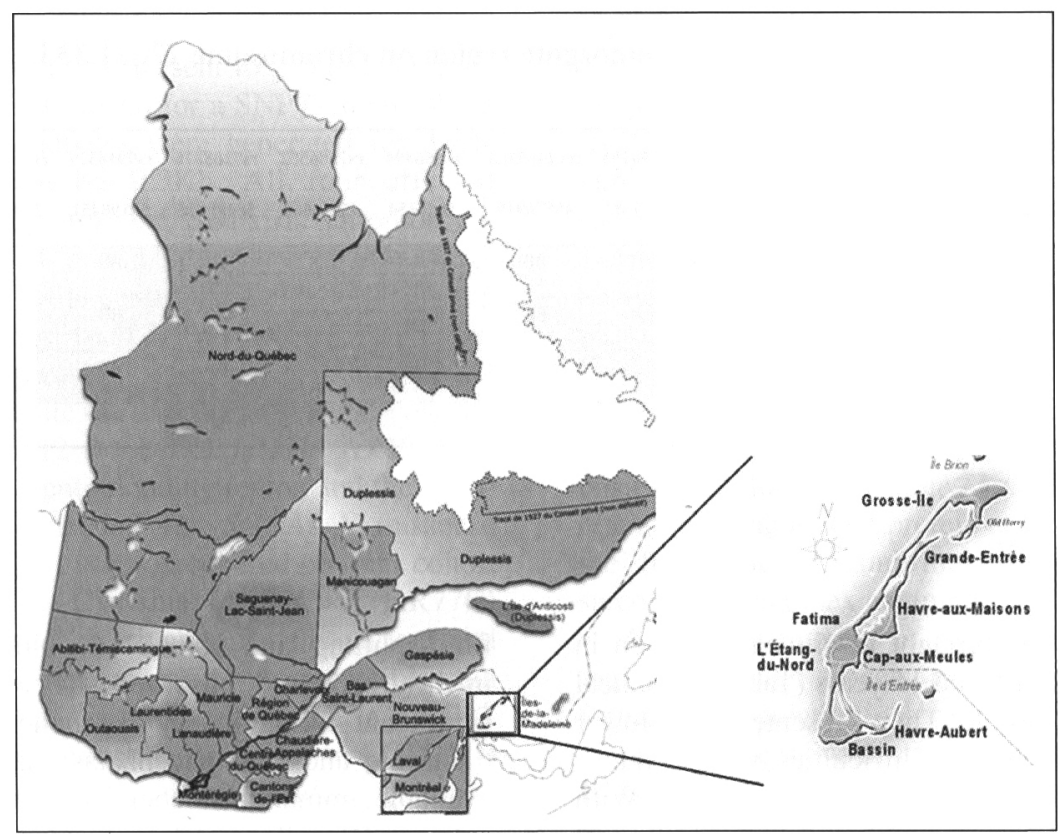

Figure 2: Geographical localization of the LGMD families. The French Canadian patients are from the Magdalen Islands, small archipelago in the St-Lawrence River.

were performed at the Genome Quebec Innovation Center, McGill University (Montreal, QC, Canada). Sequences were aligned using SeqMan 4.03 (DNAStar, Wisconsin, USA) and Mutation Surveyor v.3.1 (SoftGenetics, PA, USA). Carrier rate was estimated based on an incidence of four cases among 7826 recorded births between 1963 and 2007 in the Magdalene Islands; the frequency $q$ is the square root of $1 / 7826$. Since we are looking at the carrier frequency, ie $2 \mathrm{pq}$ and $\mathrm{p}$ is almost 1 , the carrier frequency is $2 \mathrm{X}$ the result of the above.

\section{Results}

\section{The Magdalen Islands LGMD cluster}

All cases (four living and six deceased) originate from the small archipelago of the Magdalen Islands (population 13,000), isolated in the Gulf of St-Lawrence (Figures 1,2). Only two cases were known to be closely related (I and III), though all are distantly related, often in many ways (Figure 1). Segregation clearly supports an autosomal recessive mode of inheritance. In all families, there is no history of a similar condition in the

Table 1: Clinical data on the French-Canadian cohort affected by a childhood onset LGMD

\begin{tabular}{|c|c|c|c|c|c|c|c|c|c|}
\hline Case number & I & II & III & IV & $\mathbf{V}$ & VI & VII & VIII & IX \\
\hline Age at onset & 5 & 7 & 5 & 8 & 7 & 7 & 7 & 9 & 11 \\
\hline Sex & $M$ & $\mathrm{M}$ & $F$ & $\mathrm{~F}$ & $\mathrm{~F}$ & $\mathrm{~F}$ & $\mathrm{M}$ & $\mathrm{M}$ & $F$ \\
\hline Age in 2010 (age of death) & 25 & 42 & 16 & 48 & $(34)^{2}$ & $(35)^{2}$ & $(50)^{2}$ & $(29)^{2}$ & $(68)^{1,2}$ \\
\hline Motor developmental delay & - & - & - & - & NA & NA & NA & NA & NA \\
\hline Loss of ability to walk (yrs) & 15 & 12 & 12 & 39 & 15 & 17 & 23 & 10 & 14 \\
\hline Macroglossia & + & - & + & + & NA & NA & NA & NA & NA \\
\hline Calf hypertrophy & + & + & + & + & NA & NA & + & NA & + \\
\hline Contractures & + & + & - & + & NA & NA & + & NA & NA \\
\hline Facial weakness & - & - & - & - & NA & NA & NA & NA & NA \\
\hline Cardiomyopathy & - & - & - & - & NA & NA & NA & NA & NA \\
\hline Abnormal pulmonary function & - & + & - & + & + & + & + & + & + \\
\hline Elevated CK & + & + & + & + & + & + & + & + & + \\
\hline Biopsy & & & + & + & & & & & \\
\hline
\end{tabular}

'Ventilated since age 47 years; ${ }^{2}$ Cause of death was respiratory failure; ${ }^{3}$ Sudden onset of left ventricular dysfunction, on medications; NA: not available; $\mathrm{CK}$ : Creatine Kinase 
Table 2: Haplotype results demonstrating the shared homozgote region on chromosome 17q21.33 in four affected cases

\begin{tabular}{|c|c|c|c|c|c|c|c|c|c|c|c|c|c|c|c|c|}
\hline SNP & rs223154 & rs4794786 & rs231487 & rs3760360 & rs3826397 & rs6504280 & rs4794103 & rs12453363 & rs2586494 & rs2586502 & rs7208876 & rs9914327 & rs12937672 & rs963292 & rs6503870 & rs4791250 \\
\hline position (pb) & 26952196 & 34064032 & 39336826 & 39344518 & 43864446 & 43915068 & 45575583 & 45576919 & 45628154 & 45644069 & 50190825 & 50198451 & 52179232 & 52197554 & 54014017 & 60413607 \\
\hline case I & BB & AA & AA & BB & AA & AA & BB & BB & BB & AA & BB & BB & AA & AA & AA & BB \\
\hline case II & AB & $\mathbf{A A}$ & AA & AB & AB & AA & BB & BB & BB & AA & BB & BB & AA & AB & $\mathrm{AB}$ & BB \\
\hline case III & BB & $\mathbf{A A}$ & AB & BB & AA & Ad & BB & BB & BB & AA & BB & BB & AA & AA & AA & BB \\
\hline case IV & BB & AA & AA & BB & AA & AA & BB & BB & BB & AA & BB & $\mathbf{A B}$ & $\mathbf{A A}$ & $\mathbf{A A}$ & BB & BB \\
\hline
\end{tabular}

parents. All patients were first brought to clinical attention in childhood, between the ages of 5 and 11 years (Table1). Clinical data was not available on case $\mathrm{X}$. They presented with lower extremity proximal weakness and gait difficulties, without motor milestones delay. All patients exhibited toe-walking. With gradual progression of weakness in upper and lower limbs, all patients lost their ability to walk and became wheelchairdependent at the average age of 17.4 years (range 10-39). None of the patients complained of myalgias. On exam, no one had ophthalmoplegia or facial weakness. Tongue was enlarged in the majority (3/4). Neck muscles were mildly weak. Severe proximal weakness was accompanied with less marked distal weakness in the limbs. All patients had a positive Gowers sign, calf hypertrophy and lordosis. Though scoliosis was not common, one patient required surgical correction (patient II). Cognition was normal in all individuals. Living patients have variable degrees of abnormal pulmonary function (ranging from normal to severe dysfunction, with patient II having $25 \%$ of predicted forced vital capacity). All of the deceased patients died of respiratory failure. The pulmonary function abnormalities consist of decreased vital capacity, decreased expiratory reserve and increased residual volumes reflecting weakness of the respiratory muscles. Life expectancy is clearly decreased with an average age of death of 43 years (range 29-68). One patient survived until the age of 68 , but was dependent on a respirator for the last 21 years of her life. Of interest, she had complete paralysis of her diaphragm documented on electromyelogram. Creatine kinase levels are markedly elevated early in the disease (1,800-10,000 IU), but decrease as disease progressed.

The mutation carrier rate in the Magdalen Islands is estimated to be $1 / 22$. It was calculated using the Hardy-Weinberg Equilibrium equation based on an incidence of four cases among 7826 recorded births between 1963 and 2007. This is comparable to the carrier frequency of common recessive diseases in the Saguenay-Lac Saint-Jean region of Quebec ${ }^{12}$.

\section{Pathological analysis on the Magdalene Islands patients with LGMD}

All four individuals currently alive had undergone biopsies at different ages and in different hospitals. Pathological reports were compared. All biopsies showed changes consistent with a muscular dystrophy. There was evidence of fibre-size variation, atrophied and rounded fibres, central nuclei, necrotic fibres, fibre-splitting and some basophilic fibres. Fibrosis and fat infiltration were observed. There was no evidence of a significant inflammatory component. PAS, Red oil, Gomori trichrome and acid phosphatase staining were normal. When available, immunohistochemistry was performed for dystrophin, collagen IV, collagen VI, merosin, and dysferlin, which were all normal. Immunostaining of the sarcoglycans was performed in the two most recent biopsies. In patient III, there was decreased staining for the four sarcoglycans, especially for alpha and gamma-sarcoglycan. In patient IV, decreased staining for alphasarcoglycan was noted.

\section{Genotyping and mutation analysis}

Genealogical data confirmed that all affected individuals are distantly related (Figure 1), thereby increasing the likelihood that they are homozygotes for the same ancestral mutation and flanking haplotype. We decided to use a single nucleotide polymorphisms homozyogosity mapping strategy to accelerate candidate gene identification. Seven DNA samples from four

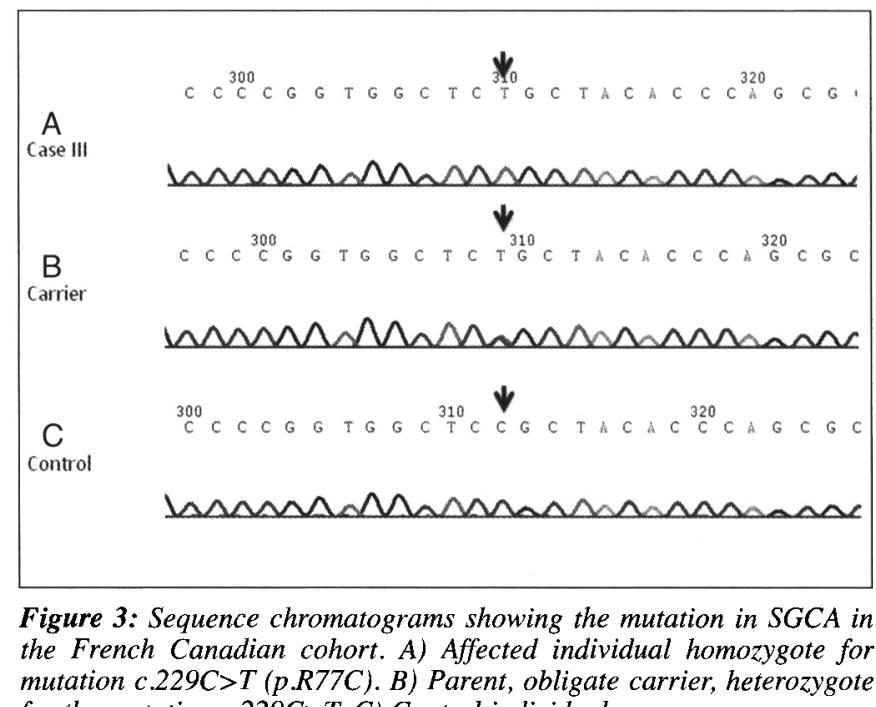

for the mutation c. $229 \mathrm{C}>T$. C) Control individual. 
affected and three unaffected participants belonging to the Magdalen Islands LGMD cohort were sent to Genome Quebec Innovation Center (Montreal, Canada) for a SNP Genome-Wide scan (GWS) (Figure 1). Genotypes were generated for $319 \mathrm{~K}$ SNPs separated on average by $9.3 \mathrm{~Kb}$. All four affected individuals were homozygote for 355 SNPs on chromosome $17 \mathrm{q} 21.31$ (Table 2). Case II had a key recombinant at the telomeric side and case IV at the centromeric side reducing the candidate interval to $6.33 \mathrm{Mb}$ (rs3826392- rs99143327). The interval contains 50 genes including $\alpha$-sarcolgycan (SGCA) responsible for LGMD2D, while the three other sarcoglycans are mapped to chromosome 13q12 (LGMD2C), 4q11 (LGMD2E) and $5 q 33.3\left(\mathrm{LGMD}_{2} \mathrm{~F}\right)^{8}$. The entire coding region and the exonintron boundaries were sequenced for $S G C A$. A missense mutation in exon 3 of $S G C A$ was uncovered in our cohort changing an Arginine for a Cysteine (c.229C>T; p.R77C) (Figure 3). All patients were homozygous for the variant and familial segregation of the disease mutation was compatible with a recessive mode of transmission. To date, the c.229C>T mutation is the most common mutation described in LGMD2D among all the reported cohorts ${ }^{10}$ (Leiden Muscular Dystrophy pages: http://www.dmd.nl/).

\section{Discussion}

\section{Clinical features of LGMD2D in the French-Canadian cohort}

In this study, we describe the first regional French-Canadian cohort affected by LGMD2D. Our cohort of distantly related French-Canadian patients of Acadian descent share the same phenotype characteristics as those typically associated with sarcoglycanopathies ${ }^{7}$. All patients presented in childhood with a progressive limb-girdle weakness, associated with macroglossia, calf pseudohypertrophy, lordosis and mild to moderate contractures. The majority of patients became wheelchair bound in late adolescence, though the age range was wide (10-39 years). Living patients exhibit various degrees of respiratory dysfunction, and all deceased patients died of pulmonary causes. Creatine kinase levels were initially elevated in all patients (1,800-10,000 U/L). Muscle biopsies showed changes compatible with a muscular dystrophy. Immunostaining against sarcoglycan proteins were available in the two most recent muscle biopsies, and this revealed decreased staining of the sarcoglycan proteins, especially the $\alpha$ and $\gamma$ sarcoglycans. This pattern of expression is often observed in patients affected by LGMD2D and it has been suggested that residual expression of the sarcoglycan complex contributes to a milder phenotype ${ }^{8}$. In our cohort, however, this correlation is not evident as both had residual staining of alpha-sarcoglycan despite an important variability in the severity of the clinical phenotype: patient III lost the ability to walk at the age of 16 whereas patient IV loss the ability to walk at the age of 39 , again, demonstrating that homozygotes carriers for the same founder recessive mutation have a very variable phenotype $\mathrm{e}^{13-15}$.

\section{Identification of disease locus and gene using a SNP genotyping approach}

To identify the gene responsible for the disease in our cohort, we have combined a regional clustering approach with SNP genotyping. In a founder population like French-Canadians, regional clustering approach has facilitated the identification of disease loci ${ }^{14-16}$. All families recruited in this cohort are from the Magdalen Islands, a small archipelago in the province of Quebec. Using genealogical data available we confirmed that all families were distantly related. Based on the likely sharing of the same founder mutation, we sent seven individuals for SNP genotyping. By homozygosity mapping analysis, we have identified a single locus (17q21-33) shared by all affected individuals $(6.33 \mathrm{Mb})$ though each case carried $17-25$ homozygote regions of more than $1 \mathrm{Mb}$. Sequencing of $S G C A$ uncovered a missense mutation in exon 3 changing an Arginine for a Cysteine (c. 229C>T; p.R77C). The substitution of a positive residue at position 77 of SGCA by a Cysteine causes retention of the mutant protein at the endoplasmic reticulum and the formation of abnormal aggregates, compromising the sarcoglycan complex assembly at the membrane ${ }^{8}$.

A growing number of neurological recessive diseases with regional founder effects are being identified in the FrenchCanadian population ${ }^{12,13,16-20}$. LGMD2D is the first founder effect for a recessive disease to be associated with the Magdalen Islands archipelago. The p.R77C mutation is the most prevalent worldwide and represents nearly one third of all reported mutations to date ${ }^{11}$; the frequency in other European populations is estimated to be $30 \%$. All four living affected individuals were homozygote for the p.R77C mutation. We presume that deceased cases were also homozygote carriers, because sequencing of unaffected family members did not uncover other variants. The frequency of the p.R77C mutation in our population implies a relative enrichment, probably due to a putative Acadian founder effect since all affected cases share a common ancestral haplotype $(6.33 \mathrm{Mb})$. This higher prevalence was also observed in Finland, another well known founder population "1. The mutation was introduced in the Finnish population much earlier since patients share a small $790 \mathrm{~Kb}$ founder haplotype, suggesting it has arise in this population 2000 years ago ${ }^{\prime \prime}$.

In this study we show that haplotype sharing in regional clusters of cases can rapidly pinpoint disease locus in the French-Canadian population. The high carrier rate for the p.R77C mutation in the Magdalen Islands will require a regional genetic counseling campaign. Furthermore, considering the genetic background of these patients, LGMD2D is likely to occur in other populations with Acadian ancestry in Canada and the United States.

\section{ACKNOWLEDGEMENTS}

The authors thank all family members for their participation. We also thank Alexandre Montpetit, Alexandre Belisle, Francois Bacot, Johanne Bégin, Francine Lachance and Sylvie D'Arcy for their collaboration. M.T. is a scholar from the Canadian Institute of Health Research (CIHR). M.S. is a scholar from the Fonds de recherche en Santé du Quebec (FRSQ). I.T. is a scholar from the CIHR and National Bank Financial Group (ETP fellowship program). The project was funded by the Muscular Dystrophy Association (MDA) and Muscular Dystrophy Canada (MDAC) Grant\# 113959. 


\section{REFERENCES}

1. Straub V, Bushby K. The childhood limb-girdle muscular dystrophies. Semin Pediatr Neurol. 2006 Jun;13(2):104-14.

2. Bushby K, Norwood F, Straub V. The limb-girdle muscular dystrophies--diagnostic strategies. Biochim Biophys Acta. 2007 Feb;1772(2):238-42.

3. Rocha CT, Hoffman EP. Limb-girdle and congenital muscular dystrophies: current diagnostics, management, and emerging technologies. Curr Neurol Neurosci Rep. 2010 Jul;10(4):267-76.

4. Wicklund MP, Mendell JR. The limb girdle muscular dystrophies: our ever-expanding knowledge. J Clin Neuromuscul Dis. 2003 Sep;5(1):12-28.

5. Gundesli H, Talim B, Korkusuz P, et al. Mutation in exon $1 \mathrm{f}$ of PLEC, leading to disruption of plectin isoform lf, causes autosomal-recessive limb-girdle muscular dystrophy. Am J Hum Genet. 2010 Dec 10;87(6):834-41.

6. Bushby KM. Making sense of the limb-girdle muscular dystrophies. Brain. 1999 Aug;122 (Pt 8):1403-20.

7. ainzof M, Bushby K. Muscle dystrophies presenting with proximal muscle weakness. In: Karpati G, Hilton-Jones D, Bushy K, Griggs RC, editors. Disorders of voluntary muscle. Cambridge: Cambridge University Press; 2010: p230-56.

8. Sandona D, Betto R. Sarcoglycanopathies: molecular pathogenesis and therapeutic prospects. Expert Rev Mol Med. 2009;11:e28.

9. Crosbie RH, Lim LE, Moore SA, et al. Molecular and genetic characterization of sarcospan: insights into sarcoglycansarcospan interactions. Hum Mol Genet. 2000 Aug 12;9(13): 2019-27.

10. Trabelsi M, Kavian N, Daoud F, et al. Revised spectrum of mutations in sarcoglycanopathies. Eur J Hum Genet. $2008 \mathrm{Jul}$; 16(7):793-803.

11. Hackman P, Vihola A, Udd B. [The kinase domain of titin controls muscle gene expression and protein turnover]. Duodecim. 2005; $121(12): 1279-80$
12. Laberge AM, Michaud J, Richter A, et al. Population history and its impact on medical genetics in Quebec. Clin Genet. 2005 Oct;68 (4):287-301.

13. Srour M, Bolduc V, Guergueltcheva V, et al. DOK7 mutations presenting as a proximal myopathy in French Canadians. Neuromuscul Disord. 2010 Jul;20(7):453-7.

14. Gosselin I, Thiffault I, Tetreault M, et al. Founder SH3TC2 mutations are responsible for a CMT4C French-Canadians cluster. Neuromuscul Disord. 2008 Jun;18(6):483-92.

15. Duquette A, Roddier K, McNabb-Baltar J, et al. Mutations in senataxin responsible for Quebec cluster of ataxia with neuropathy. Ann Neurol. 2005 Mar;57(3):408-14.

16. Bernard G, Thiffault I, Tetreault M, et al. Tremor-ataxia with central hypomyelination (TACH) leukodystrophy maps to chromosome 10q22.3-10q23.31. Neurogenetics. 2010 Oct;11(4):457-64.

17. Bolduc V, Marlow G, Boycott KM, et al. Recessive mutations in the putative calcium-activated chloride channel Anoctamin 5 cause proximal LGMD2L and distal MMD3 muscular dystrophies. Am J Hum Genet. 2010 Feb 12;86(2):213-21.

18. Thiffault I, Rioux MF, Tetreault M, et al. A new autosomal recessive spastic ataxia associated with frequent white matter changes maps to 2q33-34. Brain. 2006 Sep;129(Pt 9):2332-40.

19. Tetreault M, Duquette A, Thiffault I, et al. A new form of congenital muscular dystrophy with joint hyperlaxity maps to $3 \mathrm{p} 23-21$. Brain. 2006 Aug;129(Pt 8):2077-84.

20. Gros-Louis F, Dupre N, Dion P, et al. Mutations in SYNE1 lead to a newly discovered form of autosomal recessive cerebellar ataxia. Nat Genet. 2007 Jan;39(1):80-5. 